\title{
Evaluating the Road Safety Design through High Resolution Satellite Image: A Case Study of Karachi Metropolitan
}

\author{
Salman Zubair and Lubna Ghazal \\ Department of Geography, University of Karachi, Karachi 75270, Pakistan
}

\begin{abstract}
Humanity is suffering from numerous natural, technological and health related hazards. Urban Road crash is one of the growing health issues these days in both developed and developing countries. Pakistan stands $1^{\text {st }}$ in Asia and $48^{\text {th }}$ in the world in this regard. Similarly, the metropolitan city of Pakistan, Karachi; ranks fourth in the list. Various reasons are responsible for these crashes in Karachi. Around $34 \%$ of crashes in the city were accounted due to errors in road geometry. In this study use of high resolution satellite imagery made it possible for identifying geometrical errors at the U-turns on major arteries of the city. It was also recognized that most of the U-turns were built on the fastest lane of the roads with average distance of $1.1 \mathrm{Km}$ apart, are marked as vulnerable for considerable number of severe injury and fatal crashes. Moreover, inlet wall of all median U-turns were found broken, suggested that the car crash had occurred at least once. To cross check this observation, nearly 120 U-turns were surveyed and marked on the satellite imagery based on convenience. Trained professionals interviewed the people working/living nearby the U-turns. Out of $120 \mathrm{U}$-turns studied, $72.5 \%$ were without wall/median and $27.5 \%$ were with wall/median. Average number of people got injured or died due to crashes were statistically significant $(\mathrm{p}<0.05)$ between the above mentioned types of U-turns. In order to reduce geometrical errors use of RS (Remote Sensing) and GIS (Geographical Information System) techniques are strongly suggested to be incorporated while planning road design in the city. This would certainly save the resources particularly the lives of the people.
\end{abstract}

\section{Introduction}

The Global outbreak of road crashes mortalities and morbidities have emerged as a serious health issue. It costs more than 1.3 million lives and 20-50 million people are either being disabled or injured every year across the globe [1]. Multiple factors are responsible to vehicle collision but inappropriate road designs coupled with speedy vehicle are proven to be the key factors for serious injuries or deaths caused by road crashes [2]. Urban road environment is subjected to severe injury/fatal road crashes. This might be due to the complexity in road design and higher number of road users. Similarly, fast driving/riding in urban metropolitan could be more risky because it reduces the response time to any hazard on road, making it difficult for rider/driver for subsequent control over the vehicle.

However, controlled speed could be beneficial to road users in many ways. It does not only reduce the number as well as the severity of injury caused by the crashes but also increases the response time to road users [3]. Similarly, reduced vehicle speed could also check the fuel consumption, vehicle emission, noise and vehicle functioning cost. It is proved in various studies that controlled speed could reduce the number as well as severity of road crashes irrespective of road design in some instances [4]-[6]. Conversely, increased in travel speed is responsible to increase in the chances of crashes as well as deaths [4], [7]. Some of the studies revealed that speed limit of $14-15 \mathrm{~km} / \mathrm{h}$ is responsible to increase the chances of fatal road crashes to $15 \%$ and $26 \%$ respectively [8]. However, chances of fatality are $20 \%$ less for an adult if collided by a car moving with utmost speed of $50 \mathrm{~km} / \mathrm{h}$. Therefore, the percentage of death may increase to $60 \%$ if hit at the speed of $80 \mathrm{~km} / \mathrm{h} \mathrm{[9].} \mathrm{In} \mathrm{UK,}$ decrease in $1.6 \mathrm{~km} / \mathrm{h}$ average speed could reduce the chances of collision by $6 \%$ [10], [11]. Considering Urban environment, vehicle speed is subjected to road condition as well [12]. Smoother and wider roads compel drivers to move faster and vice versa [13], thus responsible to higher number of road crashes [14]. In Urban Environment, roads are embellished with multiple accessories. $U$-turn is an important feature that maneuvers the vehicle to 180 degree turn to direct the travel towards the opposite direction [15]. U-turns are considered as possibly highly dangerous if not situated correctly and could be responsible to greater number of vehicle crashes [16]. Globally, U-turns are considered as most unsafe road feature that is susceptible to severe injury road crashes [17]. Similarly, in Thailand U-truns are considered as one of the key contributors in road crashes and are responsible to increases the crash risk specifically on major highways of the country. In Karachi more than $30 \%$ of car crashes are accounted for error in 
road design and presence of $\mathrm{U}$ - turns are an important reason in this regard [18]. High speed of vehicles could also be responsible for higher chances of fatality to the pedestrian. If a pedestrian is being hit by a vehicle with an average speed of $60 \mathrm{~km} / \mathrm{h}, 50 \mathrm{~km} / \mathrm{h}$ or $30 \mathrm{~km} / \mathrm{h}$ than he/she would be susceptible to die with the proportion of 90, 50 and 10 percent respectively. Likewise, chances of severe injury also yield greater if a pedestrian is hit with the following proportion of increasing speed, $65 \mathrm{~km} / \mathrm{h}$, $70 \mathrm{~km} / \mathrm{h}, 75 \mathrm{~km} / \mathrm{h}$ and $80 \mathrm{~km} / \mathrm{h}$ would double, quadruple, ten times and thirty two times more the probability of severe crash [1]. Vehicular speed law is an important parameter to evaluate the occurrence of road crashes. Unfortunately, Pakistan lies among those countries where there is neither any speed limit followed nor any high speed law exists in the urban areas 'Figure 1', making difficult for the road users who face higher probability of road crashes.

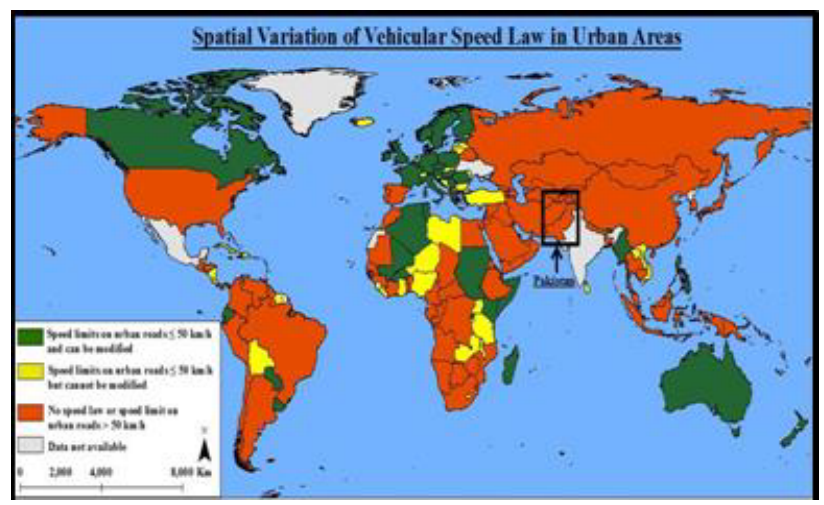

Figure 1. Variation of vehicular speed law source: After

Toroyan, 2015.

\section{Methodology}

Following work flow "Figure 2" was adopted to carry up this research.

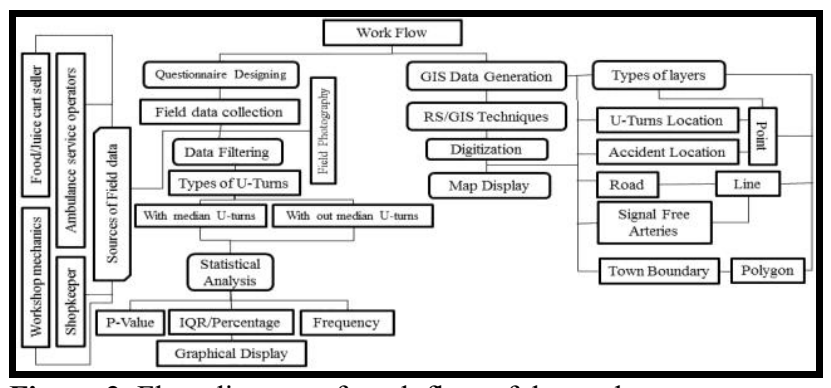

Figure 2. Flow diagram of work flow of the study.

\subsection{Field data collection}

Questionnaires were designed that hold information regarding various aspects of road crashes that include number of people injured or killed due to crash, time of crash, types of collision, days of accidents with high or low frequency. A cross-sectional interviewer-based survey was conducted to various parts of Karachi by trained investigators in year 2015. Nearly one-twenty Uturns were surveyed and minimum three people working in the close vicinity of each U-turn were interviewed. These include shop keepers, fruit cart seller, workshop mechanics, ambulance service providers who were more exposed to U-turns nearly 10 hours daily.

\subsection{Use of RS/GIS techniques}

Initially layers of road, towns and accident locations were digitized and Geo-coded data of car crashes of different years were overlaid on high resolution satellite imagery. Later on density mapping was performed to figure out the hotspots of crash areas. It was revealed that most of the Uturns proximity were showing high cluster of crashes. Similarly, with median U-turns had broken wall which is also visible on high resolution imagery, suggesting that the car crash is very common on such U-turns. That inflicted the idea of inquiring about the impact of U-turns on collision cases in Karachi. Figure 4 shows different segments of road in the city. Movement of vehicles is slowest on left lane whereas, it is fastest at the right lane. Presence of median wall reduces the space for vehicles that not only cause consistent traffic jam in rush hours but also result to serious crash cases. Insufficient road accessories made visibility of median wall extremely poor for the vehicle runner thus, ended up with collision.

\section{Results and analysis}

Data was analyzed to multiple statistical tests using Statistica Six Sigma. Firstly, data was put on two-sample Wilcoxon rank-sum test to assess the association between the average numbers of road accidents per week, average number of people got injured or died per week and the two different types of U-turns. Statistical significance was tested by two tailed test with $\mathrm{P}$ values of less than 0.05 .

Secondly, Pearson's rank correlation was applied to check the ranking order of two different types of samples. It was revealed in all the surveyed U-turns that only one correlation was found positive i.e average number of crashes per week while, rest of the two conditions were found negatively correlated. Similarly, those U-turns situated on Signal Free Arteries positive correlation were found on average number of fatalities per week. Rest of the other two conditions was negatively correlated of the given condition.

Thirdly, Chi-Square test was applied on two types of sample data sets. In this regard it was found out that all the three conditions were found statistically insignificant. Same test was also applied to the dataset extracted for Signal Free Arteries. The test showed significant relationship between the numbers of crashes took place on SFA whereas, rest of the other two conditions exhibited non-significant relationship.

Finally, Geoffrey H. Havers (GEH) test was applied to check the association of crash data. Except one variable of Morning/Evening \& Night crashes, all the other variables showed the resultant value of less than 5 that suggest the data collected for this research had a good match. However, the said variable showed the value of 6 may not be a good association of the data.

Out of those 120 U-turns survey locations, seventythree percent were without wall/median and twenty-seven percent were with wall/median. Similarly, Thirty percent 
of all the surveyed U-turns lied on SFA and rest of the seventy percent were situated other than SFA of Karachi. Mean values computed for the responses based on numerical dataset were average while frequencies were chalked out of categorical dataset that included type of severity, the time and days and types of vehicle involved in those accidents. P-values were calculated for meanweekly number of different types of road crashes i.e. only injury reported accidents and fatal accidents. The meanweekly number of accidents found statistically insignificant with $\mathrm{p}$-value is greater than 0.05 . However, mean-weekly number of injury based crashes and fatal crashes were statistically significant having P-value less than 0.05 . With-wall U-turns caused more injury based and fatal crashes than without-wall U-turns. Night time and evening hours were found out as most common times for road crashes of both types of U-turns. On without wall U-turns, occurrence of road crashes were highest on week-days i.e. (41.4\%) from Monday to Friday. However, occurrences of road crashes were observed high at all the seven days of week i.e. $(48.6 \%)$. Percentage involvement of loading pick-up, rickshaw and truck on other than SFA showed the value of $2 \%$ each. Rest of the vehicles involvement in road crashes was very meager in terms of percentage. Different types of vehicles were involved in road crashes near U-turns of both types. Involvement of cars/bike depicted the highest percentage i.e. (27\% and $37 \%$ ) on with wall and without wall U-turns. Similarly, involvements of bike on two different types of U-turns were $21 \%$ and $25 \%$ while, involvements of Bike/Car/rickshaw were $24 \%$ and $8 \%$. Whereas, cars contribution in road crashes on both types of U-turns were computed $9 \%$ and $1.1 \%$ respectively. Percentage of bike/rickshaw on without wall U-turn were 12.6 and involvement of rest of the other types of vehicles in road crashes were less than $5 \%$ near both the types of U-turns.

Table 1. Profile of road safety status.

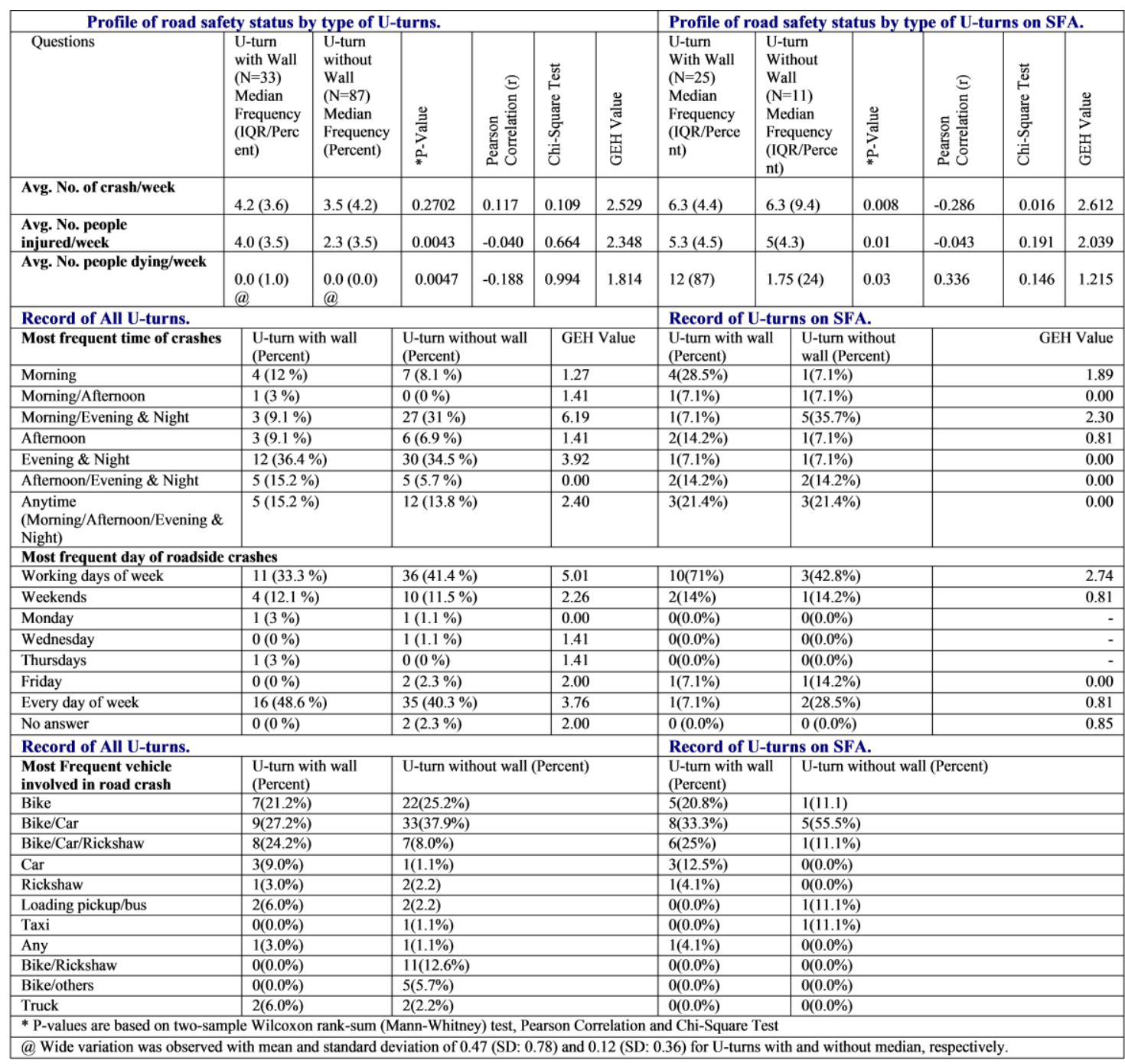

\subsection{Analysis of U-turns on signal free arteries (SFA)}

From the same data set multiple queries were applied to filter out the crash cases incurred on SFA only. On U- turns situated on SFA, number of Road crashes at withwall U-turns and without-wall U-turns were 25 and 11 respectively proved that with-wall U-turns are more susceptible to road crashes than without wall U-turns. Averaged numbers of accidents on both types of U-turns were same i.e 6.3. Similarly, average numbers of injury 
cases were nearly same i.e. 5.3 and 5.0. However, number of fatal crash showed substantial difference i.e 12 reported by the respondent near with wall U-turns, suggested that faster road are more vulnerable to road users. While, number of fatal accidents were only reported 1.75 on without wall U-turns on same arteries, proved that this type of U-turn has lesser susceptibility of collision occurrence because of their median free design. One possibility of higher number of road crashes on with wall U-turns is that median wall is situated on fastest traffic lane that reduces the reflex time of the drivers, thus increases the probability of road crashes. Responses of above three questions specifically on Signal Free Arteries were statistically significant with P-value less than 0.05 .

At the U-turns (with wall) morning hours were considered the most susceptible to road crashes (i.e. $28 \%$ ). However, on without median U-turns morning/evening and night time cases showed the highest proportion of $35 \%$. Afternoon and evening hours depicted $14 \%$ of crashes on both the types of U-turns on SFA. Unidentified times of the day were reported as $21 \%$. While, rest of the times of the day reported $7 \%$ crashes on both the types of U-turns. Different types of vehicle were involved in both types of U-turns (i.e with wall and without wall U-turns). Involvement of bike alone cause $21 \%$ and $11 \%$ crashes along with cars and rickshaw is $58 \%$ and $66 \%$ crashes on two different types of U-turns respectively. Cars alone constituent $12.5 \%$ of road crashes on with wall U-turns whereas, no case of car crash was reported on without wall U-tunrs. Loading pickup and taxi combine to cause $11 \%$ road crashes on without wall U-turns. Figure 4 shows some of the withmedian U-turns situated on different arteries of Karachi. Different colored arrows show different segments of road and arrow direction show the direction of traffic flow. Yellow arrows depict that the left lane which is the slowest traffic lane in the city. Green arrow show right most lanes in the city. It is noteworthy that most of the with-median U-turns are situated on right lane which is also the fastest traffic lane in the city that reduced the reflex time of the driver and increases the certainty of crashes. In all three figures red arrows highlight the broken walls of the with-median U-turns. It is clear from the field pictures that considerable part of the median wall has been broken which proves that the car crashes is frequent on such spots. Furthermore, consistent traffic jam is also observed on such location because median wall reduce the space of forward moving vehicles. This result to higher number of Property Damage Only (PDO) crashes.

\subsection{GIS work}

Geo-coding of 120 surveyed U-turns were done by taking their coordinates while doing the field work. Town map of Karachi was made with the help of scanned maps through different government sources. However, road network and Signal Free Arteries (SFA) were also made by digitizing on high resolution satellite imagery. It is noteworthy that SFAs initiated from peripheral parts of the city, passing through medium to high population density towns (Figure 3-b) making higher chances of road accidents within the city. Inverse Distance Weighted (IDW) technique was applied on U-turns layer in Arc GIS 10.1 environment to figure out the concentration of Uturns in Karachi (Figure 3-c). Results imply that most of the U-turns are situated on roads where fast flow of traffic is observed; therefore, increasing the risk of road crashes coupled with the injury and fatality cases. On contrary central parts of the city have fewer U-turns that reduce the chances of severe injury and fatal road crashes within the city.

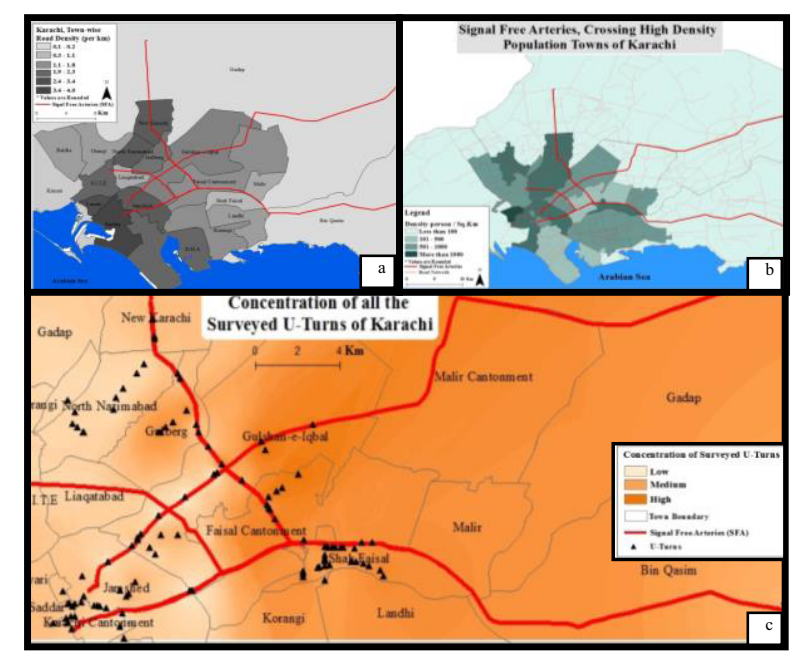

Figure 3. (a) Karachi - road density with SFA, (b) Karachipopulation density, (c) concentration of U-turns in Karachi

\section{Discussion}

Concentrating on driver skill alone for the complex issue of acquiring road safety would smog the distinction between infrastructure design and its influence on drivers. Globally, more than 1.2 million people are killed every year. This problem is the ninth leading cause of death for all-aged group people and is the leading cause of death among the group of 15-29 years age people, spoiling up to $5 \%$ GDP share in low and middle income group countries of the world. Pakistan stands first in Asia [24] in terms of leading RTA death conceiving countries of the world with more than 8,000 casualties reported in 2013 by Police. Likewise, Karachi ranks fourth [25] in this regard with more than 1,000 road accident causalities in the year 2012. It is estimated that the actual cases are much higher than the reported figures. It is because, every road accident does not get registered by the traffic police, as parties involved in such accidents resolve the conflicts on their own [26]. Results from the study suggest that with wall U-turns are more likely to encounter higher number and severe intensity of road crashes thus, causing to higher number of fatalities. Further, same U-turns are more suitable for 180 degree maneuvering of vehicle on other side of the road as compared to without wall U-turns. In Karachi most of the with wall U-turns are located on Signal Free Arteries aimed for faster traffic movement and are responsible to higher number of mortality cases. However, without wall U-turns experience lesser frequency of fatal crashes. 

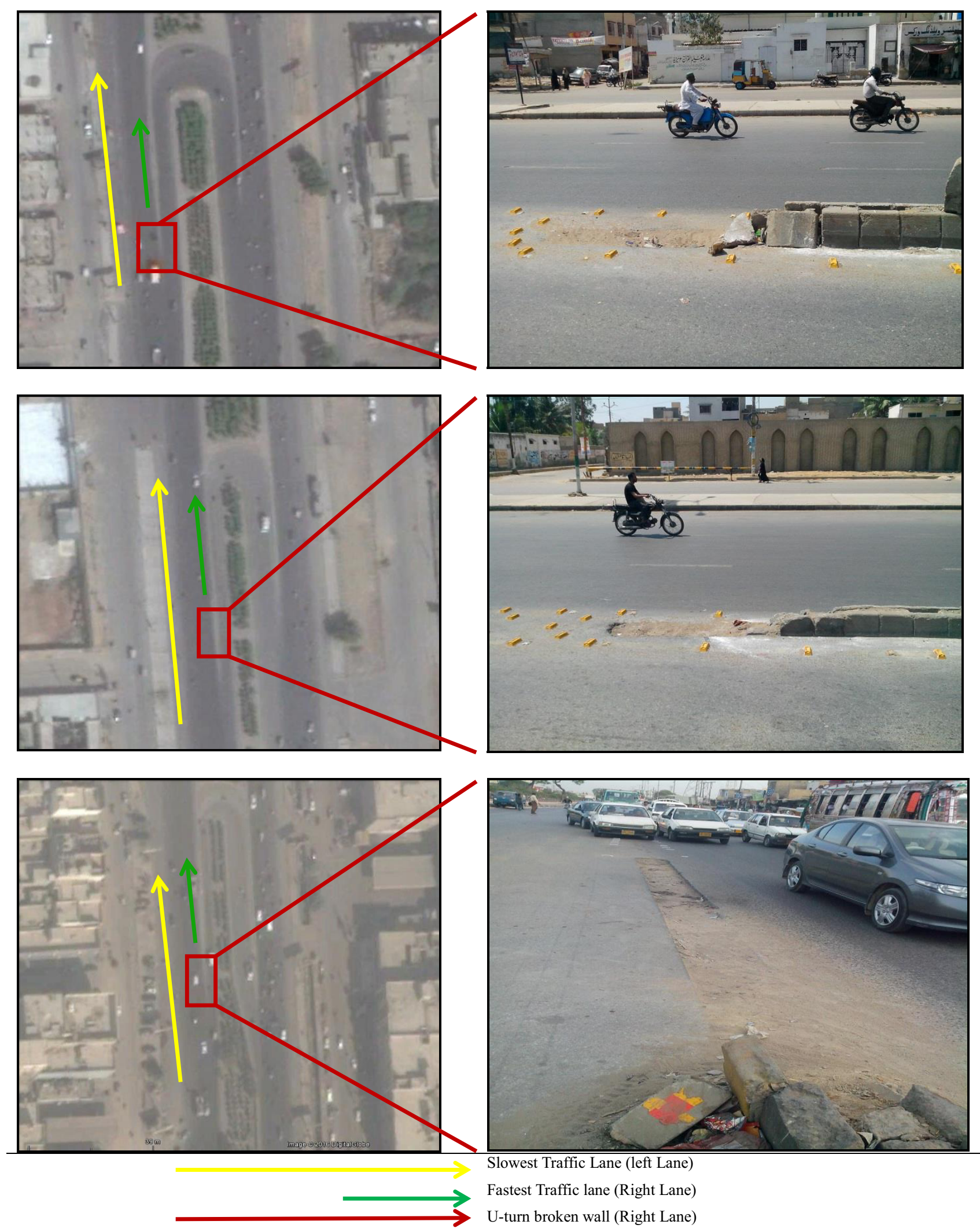

Slowest Traffic Lane (left Lane)

Fastest Traffic lane (Right Lane)

U-turn broken wall (Right Lane)

Figure 4. High resolution satellite images showing placement of U-turns.

Source: Authors

It was postulated that faster vehicular traffic are more susceptible to severe injury and fatal road crashes due to the presence of two different types of U-turns on selected arteries of the city. This shows a significant positive relationship with road crashes hence this particular feature (i.e. U-turn) on road compromise the road safety within the city.

\section{Conclusion}


It was concluded that this is the first study conducted in this region that computed the impact of U-turn on road crashes. Various statistical tests were executed then it is finally suggested that presence of U-turns especially (with-wall) is a pitfall on major arteries of the city. However, safer road design should be the top most priority for the road designers. Planners can incorporate the use of latest technologies and recent research work before taking final decision regarding changes in the infrastructure. Strong and timely coherence among different departments such as health, planning and development, traffic and communication department and academician is needed to promote the culture of productive research and concrete planning. Mass transit systems should be launched as at the earliest due to growing demand of population in Karachi. This would reduce the consumption of valuable resources as well as the adverse impact on the-environment and will certainly help to get better solutions of the real world problems like Road crashes.

\section{References}

1. T. Toroyan, "Global status report on road safety 2015," Supporting a decade of action. Geneva: World Health Organization, Department of Violence and Injury Prevention and Disability, (2015)

2. P. Thomas, A. Morris, R. Talbor, H. Fargerlind, "Identifying the causes of road crashes in Europe," Annals of advances in automotive medicine, vol. 57, p. 13, (2013)

3. A. Habibovic, J. Davidsson, "Causation mechanisms in car-to-vulnerable road user crashes: Implications for active safety systems," Accid Anal Prev, vol. 49, pp. 493-500, (2012)

4. R. Elvik, T. Vaa, A. Erke, M. Sorensen, The handbook of road safety measures: Emerald Group Publishing, (2009)

5. A.K. Lund, J.K. Wells, H.M. Baum, "Motor Vehicle Crash Fatalities and $65 \mathrm{Mph}$ Speed Limits on Rural Interstates in 40 States," (1989)

6. L. Mourad, L.-b. Patrick, V. Francoise, "Impact of Speed on Road Safety: A Times Series Analysis Approach," in Proceedings of the Road Safety on Four Continents Conference, (2005)

7. P.P. Maglio, S. Srinivasan, J.T. Kreulen, J. Spohrer, "Service systems, service scientists, SSME, and innovation," Communications of the ACM, vol. 49, pp. 81-85, (2006)

8. R. Elvik, T. Vaa, A. Hoye, M. Sorensen, "Factors contributing to road accidents," The Handbook of Road Safety Measures. Oxford, pp. 29-79, (2004)

9. E. Rosen, H. Stigson, U. Sander, "Literature review of pedestrian fatality risk as a function of car impact speed," Accid Anal Prev, vol. 43, pp. 25-33, (2011)
10. M. C. Taylor, D. Lynam, A. Baruya, The effects of drivers' speed on the frequency of road accidents: Transport Research Laboratory Crowthorne, (2000)

11. Brake, "Go 20 towards changing the default speed limit to 20mph," (2015)

12. J. Edquist, C. Rudin-Brown, M.G. Lenne, "Road design factors and their interactions with speed and speed limits," Monash University Accident Research Centre, p. 30, (2009)

13. M. Martens, S. Compte, N. A. Kaptein, "The effects of road design on speed behaviour: a literature review," (1997)

14. B. Fildes, S. Lee, "The Speed Review: Road Environment, Behaviour, Speed Limits, Enforcement and Crashes. Monash University Accident Research Centre, Prepared for Road Safety Bureau," New South Wales, and Federal Office of Road Safety, Canberra, (1993)

15. BMV. (2016), Chapter Five Safe Vehicle Operation. Available: http://www.in.gov/bmv/ files/Drivers_Manual_Chapter_5.pdf

16. I. Meel, U. Brannolte, A. Vesper, "Road Traffic Safety Evaluation At Thai U-turns Using Severity Conflict Indexes."

17. Unnamed. (2016, 05/01/2016). The U-turn as a Threat to Road Safety. Available: https://arrivealive.co.za/The-U-turn-as-a-Threat-toRoad-Safety

18. S. Zubair, S. J. H. Kazmi, "Spatial Framework for the Assessment of Road Traffic Accidents in Karachi," JBAS, vol. 9, p. 525, (2013)

19. A. Hasan, M. Mohib, "The case of Karachi, Pakistan," (2003)

20. S. Zubair, M. A. Shaikh, "U-turns and road safetyperspective from Karachi," JPMA, vol. 65, pp. 84-86, (2015)

21. R. Jooma, "Using data to save lives: Road Injury Surveillance in Karachi," RTI\&PC, Road Injury Research \& Prevention Centre, Karachi, Karachi (2013)

22. T. Mahmood, A. Wasim, A. Amir, "Title," unpublished

23. W. A. Khan. Urban Resource Centre. (2008)

24. S. Reporter. (2012, 23/09/2013). jang.com. Available: http://e.jang.com.pk/11-18-2012/karachi /page42.asp (2012)

25. Waheeduddin. (2010, 2/6/2014). The Express Tribune. Available: http:// tribune.com. pk/ story/ 26389/karachi-is-number-4-in-world-stats-ofhighest-road-fatalities/ (2010)

26. M. Shaikh, A. Shaikh, Z. Siddiqui, "Road rage and road traffic accidents among commercial vehicle drivers in Lahore, Pakistan," (2012) 